\title{
Short-period observations of speed, strain and seismicity on Ice Stream B, Antarctica
}

\author{
W.D. HARrison, K. A. Echelmeyer, \\ Geophysical Institute, University of Alaska-Fairbanks, Fairbanks, Alaska 99775-0800, U.S.A. \\ H. ENGELHARDT \\ Division of Geological and Planetary Sciences, California Institute of Technology, Pasadena, California 91125, U.S.A.
}

\begin{abstract}
The speed of Ice Stream B, Antarctica, was measured twice a day over a 1 month study period, and found to be steady at about the $\pm 3 \frac{1}{2} \%$ level, the sensitivity of the measurements. The vertical strain was measured at three sites over a 1 year period at $1 \mathrm{~h}$ intervals with sensitivities of 2 or $0.2 \mathrm{ppm}$. The strain rate varied on all time-scales. Events of high strain rate were observed, but never at more than one site at a time. They can probably be understood in terms of local modification of the strain field associated with crevassing. Diurnal variation in strain rate was observed at one and possibly two sites during two summers. The seismicity was measured at all three sites, and diurnal and seasonal variations were prominent at all, the seismicity being much more intense in winter. Several possible causes of the diurnal variations in strain and seismicity are considered: thermal and atmospheric effects, and the effects of tides in the Ross Sea.
\end{abstract}

\section{INTRODUGTION}

During recent years a great deal has been learned about the ice streams which drain the West Antarctic ice sheet through the Siple Coast, particularly Ice Stream B (Fig. 1). A summary has been given by Alley and Whillans (1991). Two characteristics of these ice streams are of particular importance to the work described here: their rapid motion, which at least at one site on Ice Stream B is known to be due to a layer of soft till at the base (Blankenship and others, 1987b; Engelhardt and others, 1990), and their seemingly unstable configuration, which appears to be subject to major changes on a time-scale of centuries, or even less (Rose, 1979; Shabtaie and Bentley, 1987; Stephenson and Bindschadler, 1988; Whillans and Bindschadler, 1988; Bindschadler and Vornberger, 1990). Both of these characteristics are shared by certain other ice masses (such as surging and tide-water glaciers), and it is known that they are at least in part due to water pressure and water storage near the bed. An indirect but relatively easy way of studying the basal water is to observe its effect on surface motion. This is a widely used technique, and changes in motion have been observed on normal valley glaciers, surge-type glaciers and tide-water glaciers over time-scales which range from hours to years. These changes have been interpreted, often quite convincingly, to give information about the hydraulics of the basal water system (e.g. Iken and others, 1983). The measurements described here were undertaken to see if variations in the motion of Ice Stream B occur on timescales from hours to a year, how they correlate with simultaneous water-pressure measurements made in boreholes, and ultimately, what they imply about processes at the bed of the ice stream.

Speed, near-surface vertical strain rate and seismicity were measured over small time intervals in the vicinity of Upstream B camp (Fig. la and b). In this area, the ice stream is moving at about $1.2 \mathrm{~m} \mathrm{~d}^{-1}$ near the center (Whillans and others, 1987), is about $1050 \mathrm{~m}$ thick, and has a temperate bed which consists, at least locally, of a soft till.

\section{SPEED - MEASUREMENT AND RESULTS}

The speed of the ice near Upstream B camp was measured repeatedly in 1988 at the site labeled "Margin" in Figure 1b. The speed of the measurement site was determined by measuring, with an electronic distance meter, the distances to two markers which were set up off the ice stream on the relatively stagnant ice of the Unicorn (Fig. 1b). These were at distances of about 6 and $9 \mathrm{~km}$. The angle between these markers was measured with a theodolite. There was sufficient information in the measurements to determine the necessary correction for the effect of the atmosphere on the speed of light, which was also checked by calculation from local temperature and pressure measurements. The accuracy of these corrections determined the accuracy of resulting speed of the ice stream. Distances were measured at intervals of typically $\frac{1}{2} \mathrm{~d}$. Over this interval, the accuracy in speed is about $\pm 3 \frac{1}{2} \%$, or $\pm 0.035 \mathrm{~m} \mathrm{~d}^{-1}$. The results are shown in Figure 2. The speed was close to $1 \mathrm{~m} \mathrm{~d}^{-1}$ and there was no significant variation during the 1 month measurement period. 

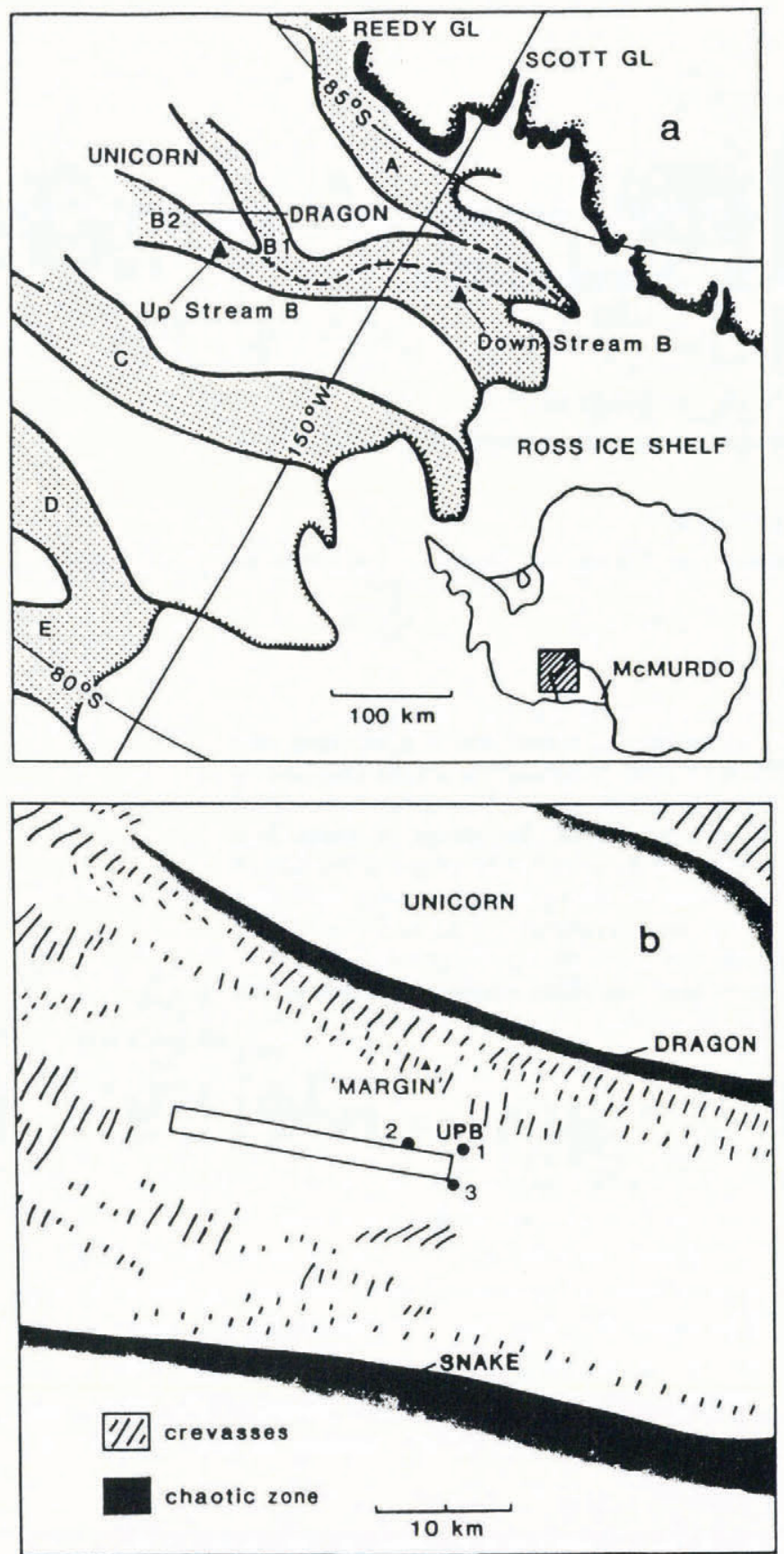

Fig. 1. a. Location map, modified from Blankenship and others (1987b) and Shabtaie and Bentley (1986). The triangle marks the site of Upstream $B$ camp. The ice streams are stippled and end at their grounding lines at the Ross Ice Shelf. b. Location of measurement sites. Speed was measured at the site labeled "Margin". Strain and seismicity were measured at sites 1 (Upstream B camp), 2 and 3. The rectangle indicates the site of the Ohio State University strain net (Whillans, 1984). The map is modified from Vornberger and Whillans (1986).

\section{STRAIN - MEASUREMENT AND RESULTS}

The vertical strain rate of the ice was measured with a simple strainmeter in which the change in length of a $1.1 \mathrm{~m}$ wire embedded in the ice (the "strain wire") is determined by measuring its change in resistance. The strain wire is connected as one arm of a Wheatstone bridge, the other three resistors of which are in the upper

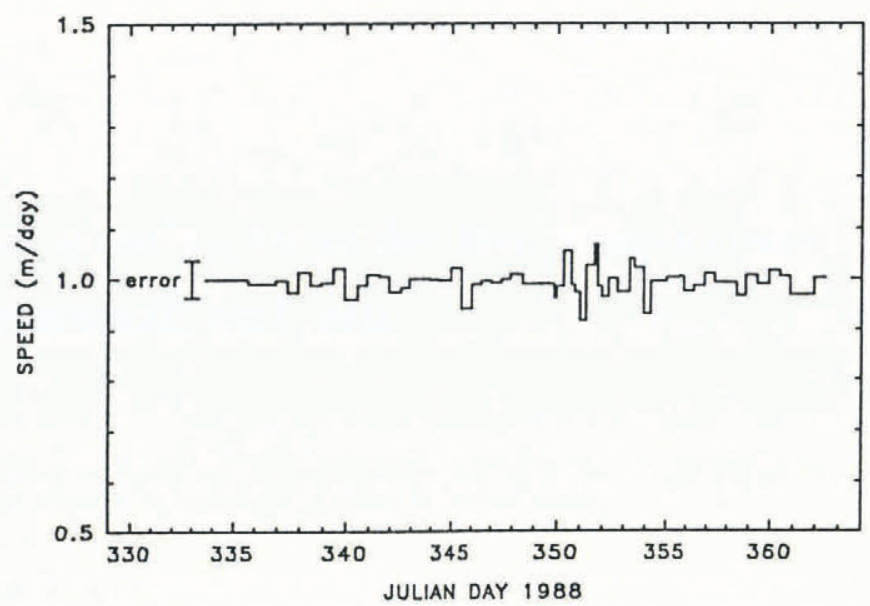

Fig. 2. Horizontal speed as a function of time. The bar shows the uncertainty in speed for a measurement interval of $\frac{1}{2} d$.

of two anchors (Fig. 3). A loosely coiled return wire connects the lower end of the strain wire to the bridge. The system is sufficiently soft (the strain wire is $0.08 \mathrm{~mm}$ in diameter) that there is little if any creep of the anchors with respect to the ice. The strainmeter is installed by lowering it on the instrument cable into a hole, immediately upon completion of drilling with hot water, and allowing it to freeze in. The weight of the lower anchor pre-tensions the wire so that operation in either tension or compression is assured. The measurements are controled by a data logger at the surface, which is programmed to give either 2 or $0.2 \mathrm{ppm}$ resolution in strain. The logger excites the bridge and records the bridge output, the change of which is simply related to the change in length of the strain wire.

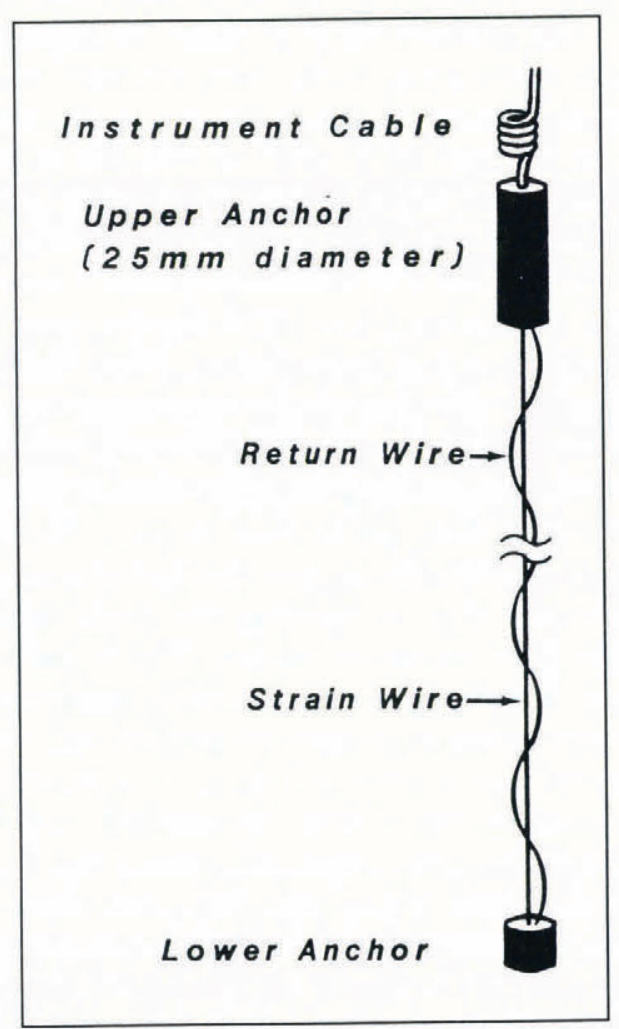

Fig. 3. Sketch of a strainmeter. 
It is straightforward to build these strainmeters but more difficult to evaluate the performance of the system (strainmeter and data logger), particularly the stability. Such an evaluation is necessary to distinguish changes in the strain of the ice from possible instrumental effects. Most of our information about performance comes from "dummy" strainmeters, ones in which the strain wire is coiled up inside the upper anchor and is therefore inactive. Most of them have been installed in the ablation areas of valley glaciers. Some dummies are stable over a period of months at the level of logger resolution, but some show a drift, usually decreasing monotonically with time, which can be on the order of 1 or even $2 \mathrm{ppm}$ in a day. Since this is the same magnitude as the vertical strain rates in the vicinity of the sites studied, one must be cautious about interpreting the results in terms of absolute strain rate, except at sites where two strainmeters give virtually identical results. On the other hand, only one dummy has ever shown any sign of instability on a diurnal time-scale or shorter, and it did so when ablation of the ice may have brought it close enough to the ice surface that the instability could be accounted for by temperature changes. We conclude that short-period changes in strain rate observed with active strain meters are probably real effects.

The strainmeters were installed at a depth of about $60 \mathrm{~m}$ at sites 1, 2 and 3 shown in Figure 1b. The water level in the holes was at a depth of typically $20 \mathrm{~m}$ before freeze-in. These depths should be compared with the spacing of crevasses and their depth at Upstream B camp, which have been quoted (Alley and others, 1987) as 150 and $25 \mathrm{~m}$, respectively. However, from our casual observations, the spacing could be up to an order of magnitude less, at least if small crevasses, which may only be found when digging pits and trenches, are included. Core studies indicate that the specific gravity of the ice is 0.90 at the depth of installation (Alley and Bentley, 1988). In summary, the strainmeters were emplaced in ice (not firn) at depths considerably deeper than the expected depths of crevasses. However, results described later suggest that the effects of crevasses may have been significant.

The results are expressed in $\mathrm{ppm} \mathrm{d}^{-1}$, because both the strain accumulating in $1 \mathrm{~d}$ and the instrumental resolution are on this order. $\left(1 \mathrm{ppmd}^{-1}=1.16 \times 10^{-11} \mathrm{~s}^{-1}=\right.$ $\left.0.365 \times 10^{-3} \mathrm{a}^{-1}\right)$.

\section{Site 2}

Figure 4 shows strain as measured by two different strainmeters in holes about $3 \mathrm{~m}$ apart at site 2 . The curvature early in the record obtained from strainmeter \#2 is a transient associated with its installation. The different slopes of the two curves imply different strain rates as measured by the two strainmeters; after day 125 , when the installation transient has probably decayed, the averages are about 0.9 and $1.2 \mathrm{ppm} \mathrm{d}^{-1}$ (positive strain rates are extensile). The difference could be either an instrumental effect, as discussed above, or a real effect indicating inhomogeneity in the strain rate on a distance scale of a few meters. Some of the high-frequency structure in the curves is shown in Figure 5. Also shown is the output of a dummy at this site. This dummy showed
SITE 2

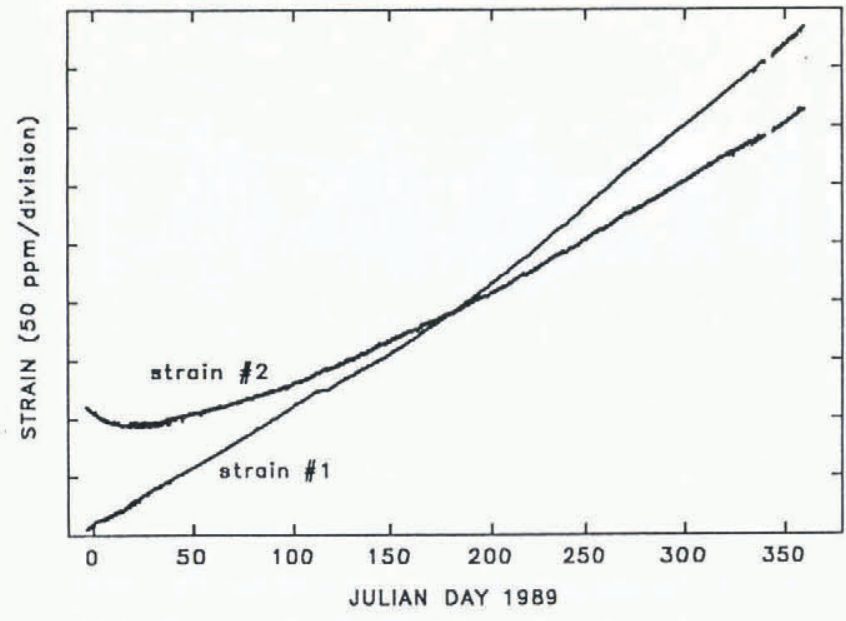

Fig. 4. Hourly strain data from two strainmeters at site 2.

a very smooth secular drift which was about $2 \mathrm{ppm} \mathrm{d}^{-1}$ immediately after its installation late in 1988, and decreased by about a factor of 10 over the following year. (Part of the initially high drift is probably due to the decay of an installation temperature transient.) The linear component of the drift has been removed in Figure 5. The data from active strainmeters \#1 and \#2 were recorded at resolutions of 0.2 and $2 \mathrm{ppm}$, respectively, the data from the dummy, at $0.2 \mathrm{ppm}$. Even though strainmeter \#1 was recorded at the same resolution as the dummy, the data are considerably noisier, which suggests that some of this noise may be the result of real fluctuations in the strain field of the ice.

Both sets of active strain data from site 2 in Figure 5 show an event between days 115 and 120 (the most prominent event seen at this site). Other correlations between the two curves can be discerned in this example and they are common throughout the record. Since there is no sign of this structure on the dummy, we take it to be real, although probably local to site 2 .

SITE 2

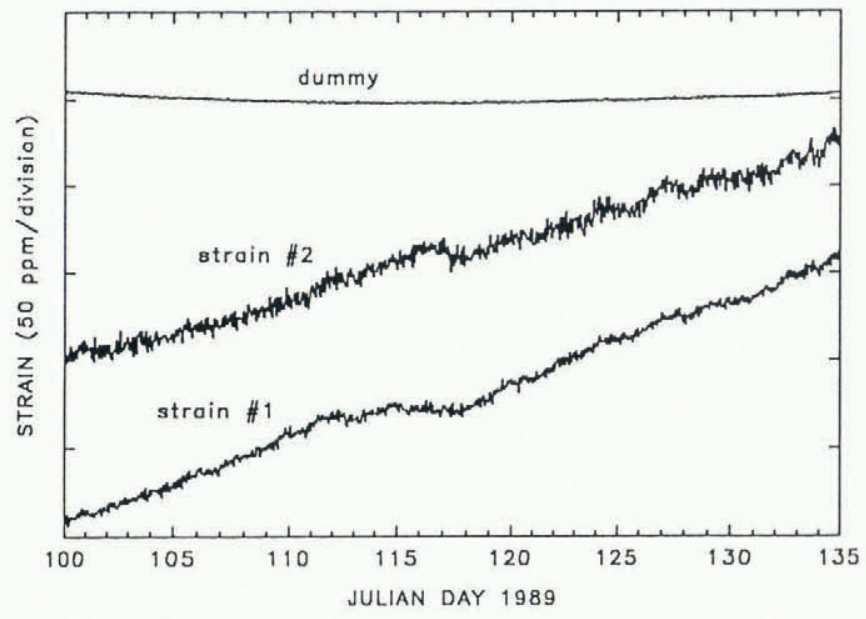

Fig. 5. Example of the structure in the strain at site 2. The dummy strainmeter was recorded at $0.2 \mathrm{ppm}$ resolution; a linear drift is removed. The active strainmeters \#1 and \#2 were recorded with resolutions of 0.2 and $2 \mathrm{ppm}$, respectively. Note that the strain scale differs from that of Figure 4. 


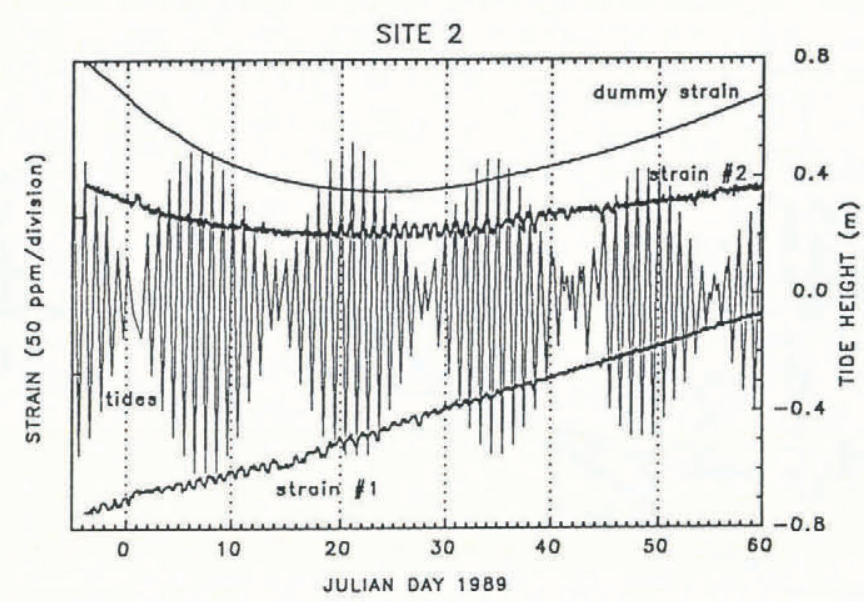

Fig. 6. Diurnal behavior of the strain on two strainmeters at site 2, and comparison with the dummy strainmeter (with a linear drift removed) and with the tide tables at McMurdo. The strain recording resolutions were the same as in Figure 5. At least part of the curvature in the dummy record is due to the decay of an installation temperature transient.

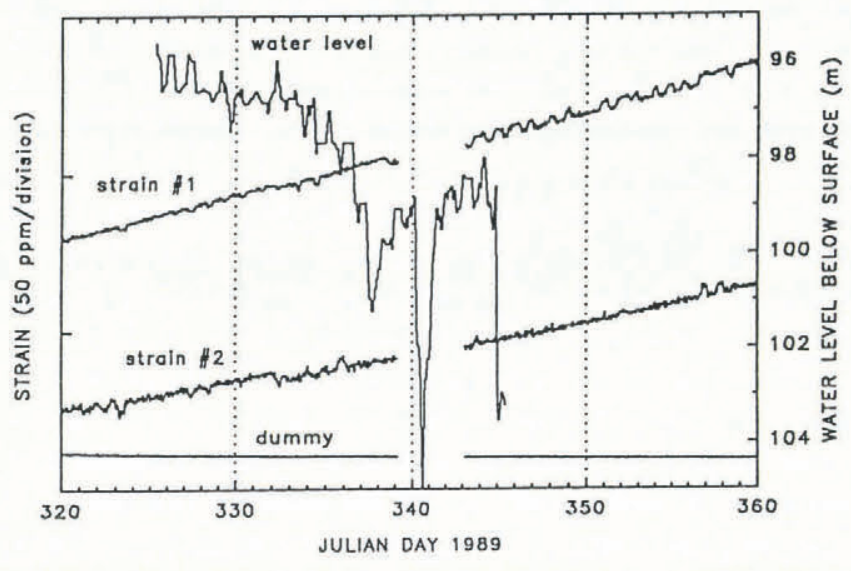

Fig. 7. Diurnal behavior of the strain rate on two strainmeters at site 2, and comparison with the dummy strainmeter (no drift removed) and the pressure in a borehole at site 1, expressed in terms of an equivalent water level below the surface of the ice stream. The strain recording resolutions were the same as in Figure 5.

Figures 6 and 7 show diurnal behavior on the two strainmeters at site 2 . The dummy at site 2 is also shown. The linear trend of its drift has been removed in Figure 6; the result is curved because the rate of dummy drift was decreasing. The maximum peak-to-peak amplitude of the diurnal variation is roughly $6 \mathrm{ppm}$, and the maximum strain occurred around midnight. There is no discernible change in phase with time. On strainmeter \#1 the diurnal behavior was present at the beginning of the record on day 362 1988, and continued to about day 38 1989. It began again about day 3241989 , and continued to the end of the record on day 3601989 . On strainmeter \#2 the behavior began about day 191989 and continued to about day 46 1989. It began again on about day 322 1989 , about the same time as on strainmeter \#1. These dates are approximate because the diurnal behavior was sometimes intermittent. At any rate, diurnal variations in strain occurred only in the austral summer. These variations seem to be real rather than, say, some artifact due to diurnal temperature variation of the logger, because, like the structure shown in Figure 5, they were not recorded by the dummy.

Two interesting features of the diurnal variations in strain are that they tend to be square and, moreover, that they possibly represent a switching between two more or less distinct strain states. This is best illustrated by the data from strainmeter \#2 in Figure 6. If the strain prior to the onset of diurnal behavior (about day 19) is extrapolated ahead in time, it coincides with the bottom of the square wave, whereas if the strain after the cessation of strong diurnal behavior (at about day 39) is extrapolated back in time, it coincides with the top of the square wave. The period of diurnal behavior could therefore be interpreted as a switching between two strain rates, with the system initially in the one state and, finally, at the end of the diurnal switching, left in the other.

An attempt was made to detect diurnal variations in the horizontal components of strain rate, using an electronic distance meter to measure base lengths of $2 \mathrm{~km}$ centered at the strain meter at site 2. None was observed but the resolution was insufficient to determine variations as small as those observed in the vertical strain rate. During the $12 \mathrm{~d}$ period of the measurements between days 348 and 360 1989, the average components of horizontal strain rate parallel and perpendicular to the flow were 2.7 and $-2.5 \mathrm{ppm} \mathrm{d}^{-1}$, respectively.

\section{Site 3}

Figure 8 shows data from site 3 , recorded at a resolution of $2 \mathrm{ppm}$. The strain rate is negative and has a greater magnitude than at site 2 (about $-6 \mathrm{ppm} \mathrm{d}^{-1}$ as inferred from the slope of the curve). The behavior for the first $75 \mathrm{~d}$ is dominated by an installation transient. The event starting on day 158 began about $3 \mathrm{~h}$ before midnight. It is not evident at site 2. Diurnal behavior was very weak, but there is some evidence for its intermittent occurrence between days 40 and 54, with peak-to-peak amplitude of about 4 ppm, and, as at site 2, maximum strain occurring near midnight.

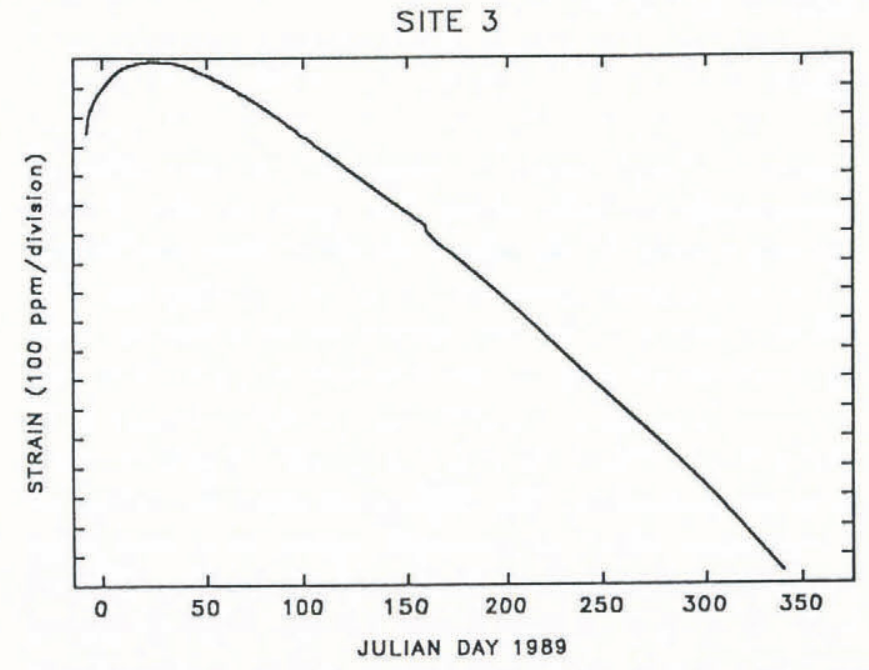

Fig. 8. Hourly strain data from site 3. 
SITE 1

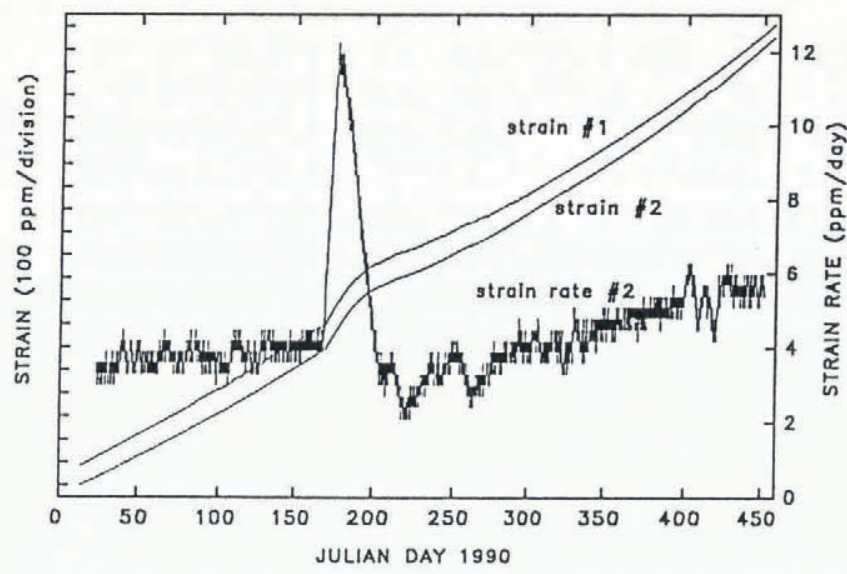

Fig. 9. Hourly strain data from two strainmeters at site 1, and the strain rate obtained by differentiation of a 1 week running average of the data from strainmeter \#2.
Seismicity was measured continuously throughout 1989 at sites 2 and 3 , and for 15 months starting early in 1990 at site 1 . Strong seasonal variation in seismicity occurred at all sites, with the minimum in the austral mid-summer, as illustrated by the data from site 3 in Figure 10. The detection systems were saturated during most of the winter because the thresholds were set to give a reasonable sensitivity in summer, when the instruments were installed. The seasonal variation of temperature, measured in the logger enclosure at site 1 , is shown in Figure 11.

Diurnal variation of seismicity also occurred at all sites, as illustrated by the data from site 3 in Figure 12a and $b$. The maximum seismicity, like the maximum strain, occurred near midnight, and there is no discernible change in phase with time. The amplitude of the diurnal variation was small in mid-summer, when the average seismicity was also weakest.

It is unknown whether the prominent strain event in Figure 9 was accompanied by a change in seismicity, because the seismicity record was saturated then.

\section{Site 1}

Figure 9 shows the strain measured on two strainmeters at site 1 (at Upstream B camp) from early in 1990 through the first 3 months of 1991 . The resolution was $2 \mathrm{ppm}$. These data were obtained after the other sites had been abandoned. The two strainmeters were placed in holes which were $0.8 \mathrm{~m}$ apart at the surface. The records are quite similar, which makes us confident that there is little instrumental drift and that it is safe to interpret the data in terms of absolute strain rate at this site. The strain rate, as obtained by differentiation of a 1 week running average of the strain measured on strainmeter \#2, is also shown in Figure 9. Its average over the entire interval is about $4.4 \mathrm{ppm} \mathrm{d}^{-1}\left(1.6 \times 10^{-3} \mathrm{a}^{-1}\right)$, but it is extremely timedependent. A prominent event, the most prominent observed at any of the sites, began near midnight between days 171 and 172 1990. The timing of its onset and its structure (except for its sign), are similar to those of the event which began at site 3 on day 1581989 . Note that the strain rate was about $50 \%$ higher at the end of the record than at the beginning. Some fine structure occurred at site 1, usually but not always the same on both strainmeters. However, there is no diurnal behavior at any time of year.

\section{SEISMICITY - MEASUREMENT AND RESULTS}

Seismicity was monitored at the three strain sites with vertical-component $8 \mathrm{~Hz}$ geophones. These were placed in the same holes used for the strainmeters. After the strainmeters had frozen in, the geophones were lowered to the former water level, at a depth of typically $20 \mathrm{~m}$, and water poured down the hole to freeze them in place. The voltage output of the geophones was monitored directly by the logger, which recorded an event when the output exceeded a programmed threshold and then rejected all signals for the next $3 \mathrm{~s}$. The resulting saturation counting rate was $1200 \mathrm{~h}^{-1}$. Counting was carried out during alternate minutes to conserve power. The accumulated counts were recorded every hour.

\section{SITE 3}

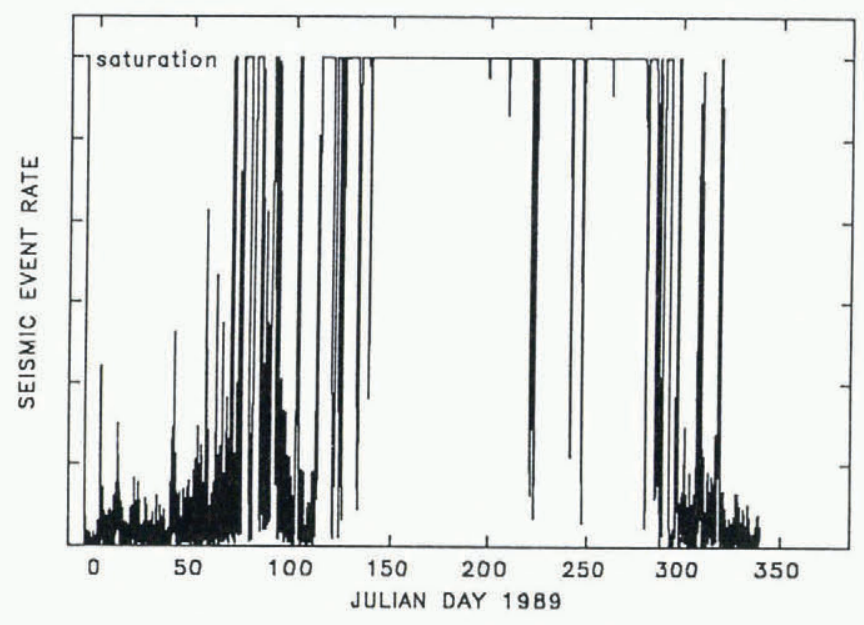

Fig. 10. Hourly seismicity data from site 3. "Saturation" corresponds to 1200 counts $h^{-1}$ of events above a given threshold.

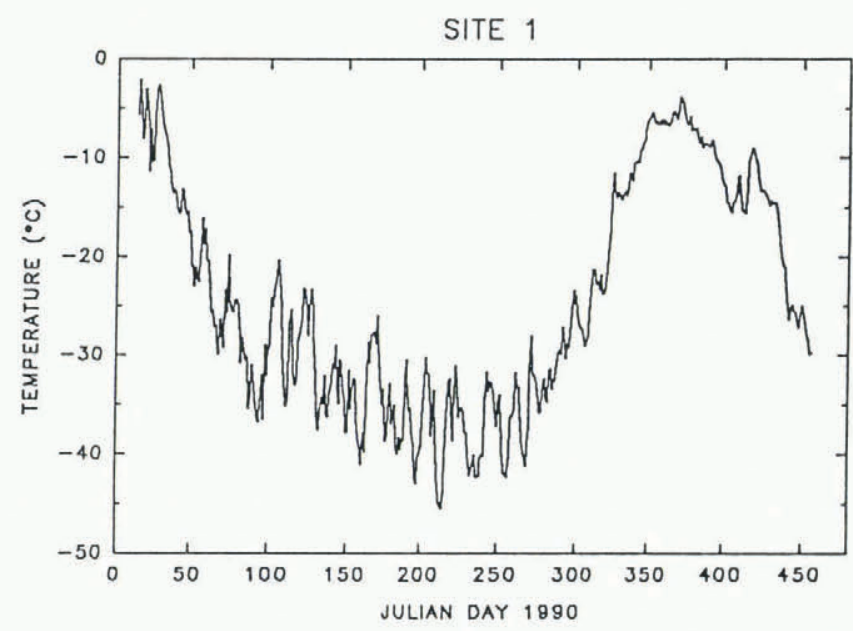

Fig. 11. Temperature inside the data logger enclosure at site 1 . 
SITE 3
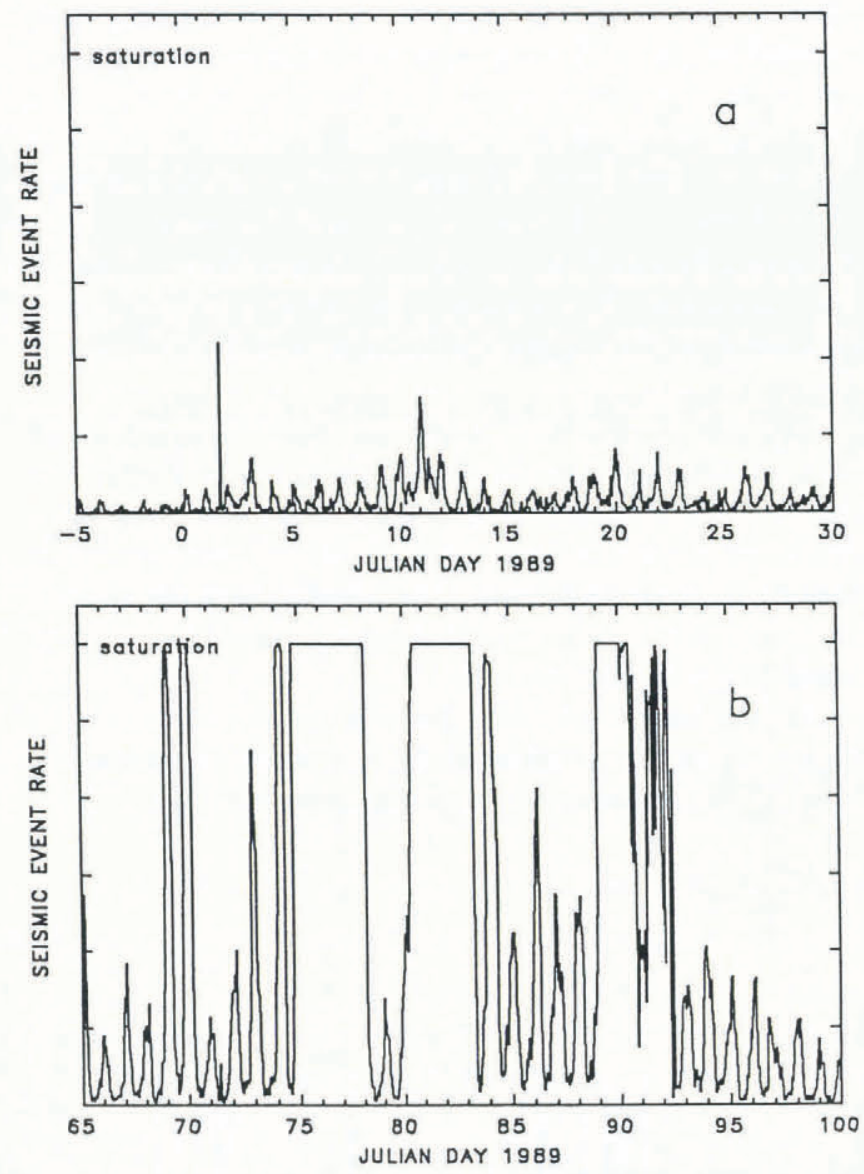

Fig. 12. Diurnal behavior in the seismicity at site 3: a. In mid-summer; $b$. Near the beginning of autumn.

\section{DISGUSSION}

\section{Speed}

Our measurements of speed were carried out over a 1 month period, the measurement intervals were typically $\frac{1}{2} \mathrm{~d}$, and the accuracy was about $3 \frac{1}{2} \%$. Earlier measurements of speed were made at Upstream B camp (McDonald and Whillans, 1992). The positioning resolution was lower but the measurements spanned a longer time period, about 2 years. These measurements, like ours, detected no significant variation in speed.

\section{Strain}

Pronounced changes in strain rate occurred, both over long time-scales (the approximately 1 year period of the records) and short time-scales (down to the $1 \mathrm{~h}$ time resolution of the measurements). The changes on the long time-scales could possibly be affected by advection of the measurement sites through a complex strain field. The reasonably well-defined events which occurred at all sites were incoherent at sites 2 and 3 (the sites that were measured simultaneously), which indicates that they were local effects. It is therefore possible that the events were caused by redistribution of the strain field due to changes in crevasses, even though the depth of measurement considerably exceeded the expected depth of the crevasses, as discussed above. The rapid change in strain rate at the beginning of some of these events (which in the case of the event in Figure 9 is smoothed by the average used to obtain the calculated strain rate shown) suggests that the events were caused by the formation of new cracks nearby. Crevassing could at least partially account for the long-term variations as well. If so, then neither the long- nor the short-term events contain information about the overall dynamics of the ice stream as determined by processes occurring at its bed, unless these processes are also local compared to the few kilometer spacing of the measurement sites.

The diurnal variations, and their often square-wave character, are more surprising. The diurnal variations of strain occurred convincingly only at site 2 , but they were probably also present at site 3 . They were not present at site 1 . They occurred the first summer, were absent the following winter and recurred the following summer. They do not seem to be instrumental effects, as discussed above. Diurnal variation in strain rate is quite common on valley glaciers in summer, when diurnal variation in water input from the surface occurs, but this cause is absent on Ice Stream B because there is no surface melting. On Barnes Ice Cap, Evans and others (1978) observed a slow variation of the horizontal components of strain rate at the surface over an $11 \mathrm{~d}$ period; its amplitude was about $2 \mathrm{ppm}^{-1}$. It was interpreted by Sanderson (1978) as due to thermal expansion in response to surface-temperature change, active in the vicinity of crevasses. This mechanism would not operate at the $60 \mathrm{~m}$ depth of the measurements on Ice Stream B, because the depth of penetration of any diurnal temperature variation is negligible in comparison. In any event, diurnal temperature changes are small at high latitude in midsummer, when the diurnal variations in strain occurred. It is also noteworthy that no diurnal variations in strain were recorded near the beginning of autumn, when diurnal variations in temperature were probably a maximum.

Since we do not have a thermal explanation for the diurnal changes in strain rate, some other possibilities are worth considering. The first is variations in atmospheric pressure. One finds that for a Young's modulus of $1.0 \times 10^{10} \mathrm{~Pa}$ for ice, a $1 \%$ change in atmospheric pressure should result in a strain of about $0.1 \mathrm{ppm}$, which is more than an order of magnitude too small to explain the observations. Even if such large diurnal variations in pressure were realistic, this is an upper limit which would apply only in the rather unlikely event that the crevasses are deep enough that the ice can be considered to be unconfined in the horizontal plane. The densification of the firn at this depth should be complete enough (Alley and Bentley, 1988) to justify our use of the value of Young's modulus for bubble-free ice.

Another possibility for the diurnal variations in strain might be tides. We have estimated the direct effect of solid-earth tides, and it appears to be much too small to be significant. However, an indirect effect of marine tides, as observed on other tide-water glaciers and ice streams, is a possibility. A correlation between marine tides and strain would suggest that tide was affecting the basal water pressure and therefore the flow of the ice stream. A tidal effect on speed was observed on Columbia Glacier, Alaska (Krimmel and Vaughn, 1987; Walters and 
Dunlap, 1987). Also, we found a good correlation between tide and speed on lower Jakobshavns Isbræ, Greenland (Echelmeyer and Harrison, 1989). The measurement sites on Ice Stream B are about $300 \mathrm{~km}$ from the grounding line, and the base of the ice stream is about $700 \mathrm{~m}$ below sea level.

The tides in the southern Ross Sea are principally diurnal (Thiel and others, 1960; Williams and Robinson, 1979; MacAyeal, 1984). Amplitude and phase vary over the Ross Ice Shelf but, using Williams and Robinson's harmonic constituents, one finds that the tides at their closest station to Ice Stream B (station "Base", roughly $200 \mathrm{~km}$ north of the grounding line) are similar to those at McMurdo (Fig. 1a) except that the amplitude at McMurdo is about a factor of 2 smaller. The pattern at McMurdo in late 1988 and early 1989, taken from the NOAA tables of high and low tides, is shown in Figure 6. The high tides, like the maxima in the strain, occur within a few hours of midnight, but there is no correlation between the amplitudes of tides and strains. Moreover, the tides continue throughout the year but the diurnal variation in strain is limited to mid-summer.

Finally, a comparison of strain and the pressure at the bed measured in boreholes near site 1 is shown in Figure 7 , in which the pressure is expressed in terms of an equivalent water level below the surface of the ice stream. A small diurnal variation in pressure is evident, although it is considered somewhat preliminary because there was no control on instrument performance (such as provided by the dummy strainmeter for the strain measurements). The variations in pressure are phase-shifted with respect to those of strain and tide; their maxima occur roughly $6 \mathrm{~h}$ after midnight, which is the time of maximum compressive strain rate.

It is difficult to make a convincing connection between the diurnal variation in strain rate and thermal effects, atmospheric effects, tide or water pressure. The connection cannot be made by virtue of frequency, since all are strongly diurnal. Moreover, there is no clear correlation between the amplitudes of strain variations and those of the other quantities. However, there is a possible explanation for the lack of correlation between amplitudes. If the strain variations are interpreted as a switching between two strain states, as discussed earlier, then there is no reason why there should be any simple connection between the amplitude of the strain variation and the amplitude of the variation of the quantity which actuates the switching (e.g. such as tide). It is possible that there is some undiscovered magnification effect, possibly related to surface conditions (such as temperature and the state of crevassing), or to conditions at the bed at some of the strain sites, which allows the diurnal variations of strain to be switched on, to observable levels, under certain conditions.

\section{Seismicity}

The ice stream is much noisier in winter than in summer at all three sites. It has been known for a long time that the noise released by seismic shooting in areas of low surface temperature is severe (e.g. Robin, 1958; Bentley, 1964). This has been interpreted by Sanderson (1978) as the release of thermal stresses, the magnitude of which increases rapidly as temperature drops. Perhaps our observations of passive seismicity could have a similar explanation. Our observations also show that the diurnal variation of seismicity is very prominent and is also related to the seasonal cycle; it is very weak in summer. An earlier observation by Kaminuma and Takahashi (1975) at Mizuho Camp, Antarctica, indicated diurnal behavior in seismicity, which was typically strongest near midnight, as measured over an interval of a few days during episodes of rapidly changing surface temperature. The seasonal variation of the diurnal behavior which we observed (small in summer, large at the beginning of autumn when diurnal changes in temperature should be large) suggests that both it and the seasonal background seismicity may have a common thermal mechanism, possibly that proposed by Sanderson, although it is worth noting that seismicity is sometimes associated with the motion of valley glaciers, rather than with thermal effects (e.g. Harrison and others, 1986).

An earlier passive seismic monitoring project at Upstream B (Blankenship and others, 1987a), had a somewhat similar motivation to ours, in that it addressed the question of the role of discrete events in the motion of the ice stream. It was concluded that brittle fracture was not a significant mechanism of energy dissipation beneath the ice stream.

\section{Strain and seismicity}

It should be recognized that the same effects could possibly explain the diurnal variation in both the strain and the seismicity. It is notable that the diurnal variations in strain occurred in summer, when the seismicity was weakest, possibly because of the lower probability of crack formation in the warmer surface. Perhaps there is a tendency in winter for any small changes in motion to be accommodated less by straining and more by cracking in winter. In summer, when there is less cracking, there may be a tendency for the changes in motion to deform the surface layer, in which case they would be more likely to be detected by the strainmeters. The sensitivity of a strainmeter to such an effect might depend upon its location relative to crevasse patterns.

\section{SUMMARY}

No variation in the speed of Ice Stream B was detected in twice-daily measurements carried out over a 1 month interval with an accuracy of a few per cent. However, diurnal and seasonal variations in both the near-surface vertical strain rate and the seismicity were observed, as were long-term changes in the strain rate. The seismicity was intense in winter. The diurnal variations in strain were weak, tended to have the character of square waves and were observed only in summer. The instrumental controls were good enough that these characteristics seem to be real. Both the seismicity and the strain have their maxima near midnight. It is possible that the diurnal variations of strain and seismicity have a common cause, or it could be, for example, that the diurnal variations in seismicity are due to thermally induced near-surface cracking as suggested by Sanderson (1978), and that the 
variations in strain rate are due to changes in the motion of the ice stream which were too small to be detected in our direct measurements of speed. The effect of tides (via their diurnal influence on subglacial water pressure and therefore on the motion of the ice stream), thermal stresses and the locations of strain sites with respect to crevasses may be significant. Preliminary measurements of water pressure in boreholes drilled by the California Institute of Technology do suggest a small diurnal variation in pressure, phase-shifted roughly $6 \mathrm{~h}$ with respect to the variations in strain. If tides are affecting the motion of Ice Stream B, as has been observed on other ice streams and glaciers, then there would be some interesting implications for the basal hydraulic system.

In addition to the diurnal and seasonal behavior, several reasonably well-defined strain events were observed, but none was coherent between different sites. These events are probably related to changes in crevasses and, if so, are not representative of large-scale variations in flow. The lack of coherent events is in contrast to what has been observed on some other fast-moving ice masses, such as surging glaciers, where they seem to be associated with coherent instabilities in the basal drainage system (e.g. Kamb and others, 1985). The basal drainage system of Ice Stream B is evidently relatively stable.

\section{DATA AVAILABILITY}

The data described in this paper are available on a disk from the authors or from World Data Center A: Glaciology.

\section{ACKNOWLEDGEMENTS}

We are grateful to B. Koci of the Polar Ice Coring Office for drilling some of the holes for us, to K. Petersen for recovering the data from site 1 , and for the comments of several reviewers. Financial support was through the U.S. National Science Foundation, grant DPP-8716604.

\section{REFERENCES}

Alley, R. B. and C. R. Bentley. 1988. Ice-core analysis on the Siple Coast of West Antarctica. Ann. Glaciol., 11, 1-7.

Alley, R. B. and I. M. Whillans. 1991. Changes in the West Antarctic ice sheet. Science, 254 (5034), 959-963.

Alley, R. B., D. D. Blankenship, C. R. Bentley and S. T. Rooney. 1987. Till beneath Ice Stream B. 3. Till deformation: evidence and implications. F. Geophys. Res., 92 (B9), 8921-8929.

Bentley, C. R. 1964. The structure of Antarctica and its ice cover. In Odishaw, H., ed. Research in geophysics. Vol. 2. Solid earth and interface phenomena. Cambridge, MA, M.I.T. Press, 335-389.

Bindschadler, R.A. and P.L. Vornberger. 1990. AVHRR imagery reveals Antarctic ice dynamics. EOS, 71 (23), 741-742.
Blankenship, D. D., S. Anandakrishnan, J. L. Kempf and C. R. Bentley. 1987a. Microearthquakes under and alongside Ice Stream B, Antarctica, detected by a new passive seismic array. Ann. Glaciol., 9, 30-34.

Blankenship, D. D., C. R. Bentley, S. T. Rooney and R. B. Alley. 1987b. Till beneath Ice Stream B. 1. Properties derived from seismic travel times. F. Geophys. Res., 92 (B9), 8903-8911.

Echelmeyer, K. and W. Harrison. 1989. Dynamics of Jakobshavns ice stream, West Greenland. (Abstract.) Ann. Glaciol., 12, 201.

Engelhardt, H., N. Humphrey, B. Kamb and M. Fahnestock. 1990. Physical conditions at the base of a fast moving Antarctic ice stream. Science, 248 (4951), 57-59.

Evans, K., D.J. Goodman and G. Holdsworth. 1978. Recording wire strainmeters on the Barnes Ice Cap, Baffin Island, Canada. $\mathcal{F}$. Glaciol., 20(83), 409-423.

Harrison, W. D., C. F. Raymond and P. MacKeith. 1986. Short period motion events on Variegated Glacier as observed by automatic photography and seismic methods. Ann. Glaciol., 8, 82-89.

Iken, A., H. Röthlisberger, A. Flotron and W. Haeberli. 1983. The uplift of Unteraargletscher at the beginning of the melt season - a consequence of water storage at the bed? f. Glaciol., 29(101), 28-47.

Kamb, B. and 7 others. 1985. Glacier surge mechanism: 1982-1983 surge of Variegated Glacier, Alaska. Science, 227(4686), 469-479.

Kaminuma, K. and M. Takahashi. 1975. Iceshock swarms observed at Mizuho camp, Antarctica. Antarct. Rec., 54, 75-83.

Krimmel, R. M. and B.H. Vaughn. 1987. Columbia Glacier, Alaska: changes in velocity 1977-1986. J. Geophys. Res., 92 (B9), 8961-8968.

MacAyeal, D. R. 1984. Numerical simulations of the Ross Sea tides. $\mathcal{F}$. Geophys. Res., 89(C1), 607-615.

McDonald, J. and I. M. Whillans. 1992. Search for temporal changes in the velocity of Ice Stream B, West Antarctica. F. Glaciol., 38(128), 157-161.

Robin, G. de Q 1958. Glaciology. III. Seismic shooting and related investigations. Norwegian-British-Swedish Antarctic Expedition, 1949-52. Scientific Results, 5.

Rose, K.E. 1979. Characteristics of ice flow in Marie Byrd Land, Antarctica. F. Glaciol., 24(90), 63-75.

Sanderson, T.J. O. 1978. Thermal stresses near the surface of a glacier. f. Glaciol., 20(83), 257-283.

Shabtaie, S. and C. R. Bentley. 1986. Ice streams and grounding zones of West Antarctica and the Ross Ice Shelf. (Abstract.) Ann. Glaciol., 8, 199-200.

Shabtaie, S. and C.R. Bentley. 1987. West Antarctic ice streams draining into the Ross Ice Shelf: configuration and mass balance. $\mathcal{F}$. Geophys. Res., 92(B2), 1311-1336.

Stephenson, S.N. and R.A. Bindschadler. 1988. Observed velocity fluctuations on a major ice stream. Nature, 334(6184), 695-697.

Thiel, E., A. P. Crary, R. A. Haubrich and J.C. Behrendt. 1960. Gravimetric determination of ocean tide, Weddell and Ross Seas, Antarctica. 7. Geophys. Res., 65(2), 629-636.

Vornberger, P. L. and I. M. Whillans. 1986. Surface features of Ice Stream B, Marie Byrd Land, West Antarctica. Ann. Glaciol., 8, 168170.

Walters, R. A. and W. W. Dunlap. 1987. Analysis of time series of glacier speed: Columbia Glacier, Alaska. F. Geophys. Res., 92(B9), 89698975.

Whillans, I. M. 1984. Ice stream dynamics. Antarct. F. U.S., 19(5), 5153.

Whillans, I.M. and R.A. Bindschadler. 1988. Mass balance of Ice Stream B, West Antarctica. Ann. Glaciol., 11, 187-193.

Whillans, I. M., J. Bolzan and S. Shabtaie. 1987. Velocity of Ice Streams B and C, Antarctica. F. Geophys. Res., 92(B9), 8895-8902.

Williams, R.T. and E.S. Robinson. 1979. Ocean tide and waves beneath the Ross Ice Shelf, Antarctica. Science, 203(4379), 443-445.

The accuracy of references in the text and in this list is the responsibility of the authors, to whom queries should be addressed. 